\title{
Thermo physical chemical properties of fluids using the free NIST chemistry web book database
}

\begin{abstract}
Many engineers, students, teachers, academicians, scientists, and researchers need to know intensive thermal, physical, and chemical properties of a fluid at a certain equilibrium state (as determined by temperature and pressure, for example). Such properties include the density, specific volume, viscosity, specific heat capacity, thermal conductivity, speed of sound, specific enthalpy, specific entropy, and surface tension. This article refers to a powerful database for such information, which is called NIST Chemistry Web Book. It is owned by the National Institute of Standards and Technology (NIST), which is an agency of the United States Department of Commerce. The database is available online free-of-charge and does not require registration for access. Its use is simple, and it offers the user multiple options for the unit to be used for each individual property. An application is presented where the density, dynamic viscosity, specific heat at constant pressure, and thermal conductivity for water at its liquid phase are presented at an absolute pressure of 1 bar over a temperature range from $1^{\circ} \mathrm{C}$ to $99^{\circ} \mathrm{C}$. Comparisons with two sources support the correctness of the database.
\end{abstract}

Volume I Issue I - 2017

\author{
Osama A Marzouk \\ College of Engineering, University of Buraimi, Oman
}

Correspondence: Osama A Marzouk, University of Buraimi, College of Engineering ,P.O. Box 890, P.C. 5I2, Al Buraimi, Sultanate of Oman, Email osama.m@uob.edu.om

Received: May 20, 2017| Published: August 28, 2017

Keywords: fluids, properties, thermal. physical, chemical, water

Abbreviations: IR, infrared; UV, ultraviolet (visible); IUPAC, international union of pure and applied chemistry; InChI, international chemical identifier; InChIKey, new fixed-length code that represents a InChI; CAS, chemical abstracts service; NIST, national institute of standards and technology; SRD, standard reference data.

\section{Introduction}

Fluids (gases and liquids) are encountered heavily in different specializations of engineering and science. Engineers and researchers may frequently need an easy access to a reliable and rich database of fluid properties at a wide range of conditions during their work. Example uses are the design of plumbing systems, ventilation or airconditioning systems, cooling cycles, and structures subject to wind loads, plasma flows, and various chemical processes. In teaching, the data in an appendix of a textbook might be sufficient to meet the need of a course. However, a much deeper and boarder database is needed to satisfy the scope of practical applications, especially with multidisciplinary nature. This work explores one such extensive database, showing how powerful it is. Being freely available online and well-documented increases its value. A specific example for using it is provided for liquid water as a sample fluid.

\section{NIST chemistry web book}

The National Institute of Standards and Technology (NIST) developed a program called Standard Reference Data (SRD), ${ }^{1}$ which covers chemistry, engineering, fluids and condensed phases, material sciences, mathematics, computer sciences, and physics. One component of this program is called NIST Chemistry Web Book, ${ }^{2}$ which is a rich database that offers several thermo-physical-chemical properties of fluids and other species.

The information in the database spans (as of July 29, 2017) the following categories:

A. Thermophysical property data for 74 fluids

\section{i. Density, specific volume}

ii. Heat capacity at constant pressure

iii. Heat capacity at constant volume

iv. Specific enthalpy

v. Specific internal energy

vi. Specific entropy

vii. Dynamic viscosity

viii. Thermal conductivity

ix. Joule-Thomson coefficient

x. Surface tension (saturation curve only)

xi. Speed of sound

B. Thermochemical data for over 7,000 organic and small inorganic compounds

i. Enthalpy of formation

ii. Enthalpy of combustion

iii. Heat capacity

iv. Entropy

v. Phase transition enthalpies and temperatures

vi. Vapor pressure

vii. Reaction Thermochemistry data for over 8,000 reactions

viii. Enthalpy of reaction

ix. Free energy of reaction

x. Ion Energetics data for over 16,000 compounds

xi. Ionization energy 

xii. Appearance energy
xiii. Electron affinity
xiv. Proton affinity
xv. Gas basicity
xvi. Cluster ion binding energies
C. IR spectra for over 16,000 compounds
D. UV/Vis spectrum
E. Constants of diatomic molecules (spectroscopic data) for over 600 compounds
F. Gas chromatography data for over 27,000 compounds. ${ }^{3-6}$
The following fluids are among the ones in the NIST Chemistry Web Book database shown in Table 1. For fluids, some temperature- dependent properties can be displayed in a tabular form or as an interactive graph (which can be saved as a PNG image file shown in Figures 1-8. The database provides proper references that support the data presented for each fluid. One can specify the fluid (or the chemical species in general) by any of five methods as explained in Table 2, with the values of water being given as an example.

Table I List of fluids in NIST chemistry web book database

\begin{tabular}{|c|c|c|c|}
\hline I & Water & 31 & Decane \\
\hline 2 & Nitrogen & 32 & Dodecane \\
\hline 3 & Hydrogen & 33 & Helium \\
\hline 4 & Parahydrogen & 34 & Neon \\
\hline 5 & Deuterium & 35 & Argon \\
\hline 6 & Oxygen & 36 & Krypton \\
\hline 7 & Fluorine & 37 & Xenon \\
\hline 8 & Carbon monoxide & 38 & Ammonia \\
\hline 9 & Carbon dioxide & 39 & Nitrogen trifluoride \\
\hline 10 & Dinitrogen monoxide & 40 & Trichlorofluoromethane (RII) \\
\hline II & Deuterium oxide & 41 & Dichlorodifluoromethane (RI2) \\
\hline 12 & Methanol & 42 & Chlorotrifluoromethane (RI3) \\
\hline 13 & Methane & 43 & Tetrafluoromethane (RI4) \\
\hline 14 & Ethane & 44 & Dichlorofluoromethane (R2I) \\
\hline 15 & Ethene & 45 & Methane, chlorodifluoro- (R22) \\
\hline 16 & Propane & 46 & Trifluoromethane (R23) \\
\hline 17 & Propene & 47 & Methane, difluoro- (R32) \\
\hline 18 & Propyne & 48 & Fluoromethane (R4I) \\
\hline 19 & Cyclopropane & 49 & $\begin{array}{l}\text { I,I,2-Trichloro-I,2,2-trifluoroethane } \\
\text { (RII3) }\end{array}$ \\
\hline 20 & Butane & 50 & $\begin{array}{l}\text { I,2-Dichloro-I,I,2,2- } \\
\text { tetrafluoroethane (RI|4) }\end{array}$ \\
\hline 21 & Isobutane & 51 & Chloropentafluoroethane (RII5) \\
\hline 22 & Pentane & 52 & Hexafluoroethane (RII6) \\
\hline
\end{tabular}

\begin{tabular}{|c|c|c|c|}
\hline 23 & 2-Methylbutane & 53 & $\begin{array}{l}\text { Ethane, 2,2-dichloro- I, I, I-trifluoro- } \\
\text { (RI23) }\end{array}$ \\
\hline 24 & 2,2-Dimethylpropane & 54 & $\begin{array}{l}\text { Ethane, I-chloro-I,2,2,2-tetrafluoro- } \\
\text { (RI24) }\end{array}$ \\
\hline 25 & Hexane & 55 & Ethane, pentafluoro- $(\mathrm{R} / 25)$ \\
\hline 26 & 2-Methylpentane & 56 & Ethane, I, I, I,2-tetrafluoro- (RI34a) \\
\hline 27 & Cyclohexane & 57 & I, I-Dichloro-I-fluoroethane (RI4Ib) \\
\hline 28 & Heptane & 58 & I-Chloro-I, I-difluoroethane (R I42b) \\
\hline 29 & Octane & & \\
\hline 30 & Nonane & & \\
\hline
\end{tabular}

Table 2 The five methods to specify a fluid in NIST chemistry web book

\begin{tabular}{|c|c|}
\hline $\begin{array}{l}\text { Specification method of } \\
\text { a fluid }\end{array}$ & Example for water \\
\hline Name & Water \\
\hline Chemical formula & $\mathrm{H}_{2} \mathrm{O}$ \\
\hline IUPAC ${ }^{3}$ identifier string $\ln C h l^{4}$ & $\mathrm{IS} / \mathrm{H}_{2} \mathrm{O} / \mathrm{hIH}$ \\
\hline $\begin{array}{l}\text { IUPAC identifier string } \\
\text { InChIKey }\end{array}$ & XLYOFNOQVPJJNP-UHFFFAOYSA-N \\
\hline $\mathrm{CAS}^{6}$ registry number & $7732-18-5$ \\
\hline \multicolumn{2}{|c|}{ 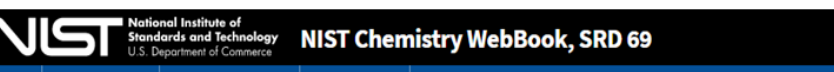 } \\
\hline NIST Data Y & \\
\hline
\end{tabular}

Search for Species Data by Chemical Formula

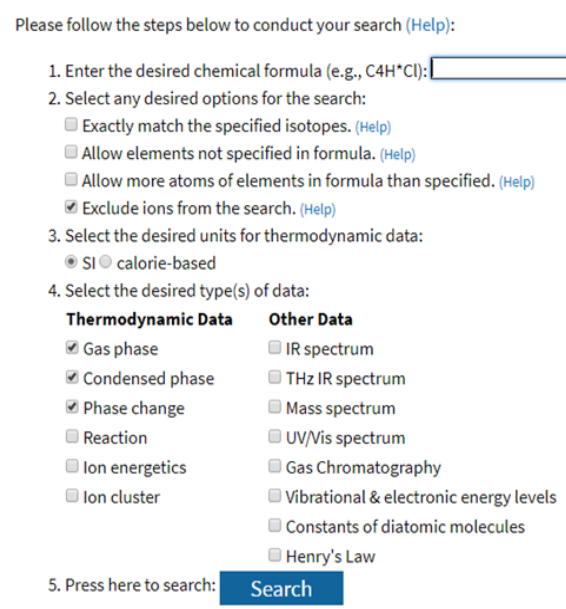

Figure I A snapshot of the online database (NIST Chemistry WebBook) when selecting a species by its chemical formula.

\section{Some water properties}

We consider here liquid-water as an example fluid and present the variation of four thermo physical properties that are commonly used in some engineering disciplines with temperature at a constant pressure of 1 bar $\left(10^{5} \mathrm{~Pa}\right)$, which is approximately equal to one standard atmosphere $(101,325 \mathrm{~Pa})$. The temperature range is from $1^{\circ} \mathrm{C}$ to $99^{\circ} \mathrm{C}$. The properties are:

a. Density (in $\mathrm{kg} / \mathrm{m}^{3}$ ) 

b. Dynamic/Absolute viscosity (in centipoises, $\mathrm{cP}$ );
c. Specific heat at constant pressure (in $\mathrm{J} / \mathrm{g} .{ }^{\circ} \mathrm{C}$ )
d. Thermal conductivity (in $\mathrm{W} / \mathrm{m} .{ }^{\circ} \mathrm{C}$ )
e. Specific volume $\left(\right.$ in $\left.\mathrm{cm}^{3} / \mathrm{g}\right)$
f. Kinematic viscosity (in centistokes, $\mathrm{cSt}$ )
g. Specific heat at constant volume (in $\mathrm{J} / \mathrm{g} .{ }^{\circ} \mathrm{C}$ )
h. Speed of sound $(\mathrm{Inm} / \mathrm{s})$

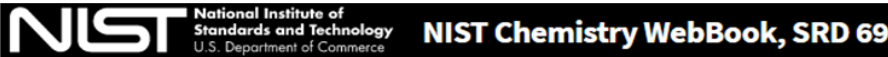
A Search
NIST Data V
About $\mathbf{r}$

\section{Search Results}

5 matching species were found.

For each matching species the following will be displayed:

- Chemical name

- Chemical formula

- Structure image (if available)

Click on the name to see more data.

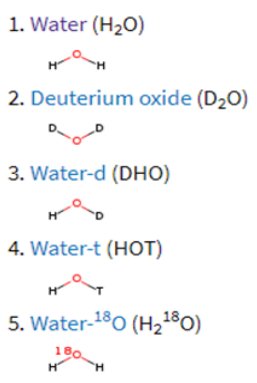

Figure $2 \mathrm{~A}$ snapshot of the online database (NIST Chemistry Web Book) showing the search results for the chemical formula, $\mathrm{H}_{2} \mathrm{O}$.

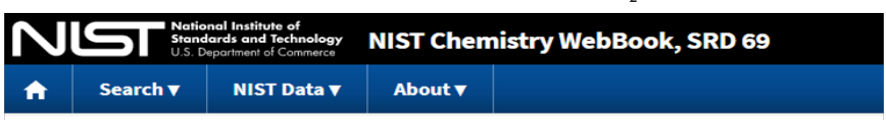

\section{Water}

- Formula: $\mathrm{H}_{2} \mathrm{O}$

- Molecular weight: 18.015

- IUPAC Standard InChI:

- InChI=1S/H2O/h1H2

InChITRUST

- IUPAC Standard InChIKey: XLYOFNOQVPJJNP-UHFFFAOYSA-N

- CAS Registry Number: 7732-18-5

- Chemical structure:

This structure is also available as a $2 \mathrm{~d}$ Mol file or as a computed 3d SD file

The $3 \mathrm{~d}$ structure may be viewed using Java or Javascript.

- Isotopologues:

- Deuterium oxide

- Weuteriur

- Water-180

- Water-d

Water-t

Deuterium oxide

- Other names: Water vapor; Distilled water; Ice; H2O; Dihydrogen oxide; steam; Tritiotope

- Permanent link for this species. Use this link for bookmarking this species for future reference.

- Information on this page:

- Gas phase thermochemistry data

Condensed phase thermochemistry data

- Phase change data

- References

Referenc

- Other data available:

Figure $3 \mathrm{~A}$ snapshot of the online database (NIST Chemistry Web Book) after selecting water.

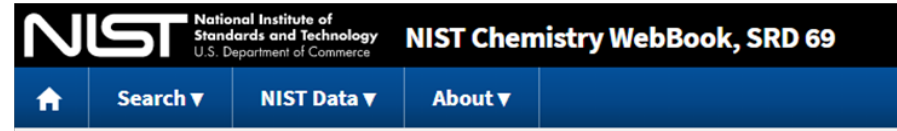

\section{Thermophysical Properties of Water}

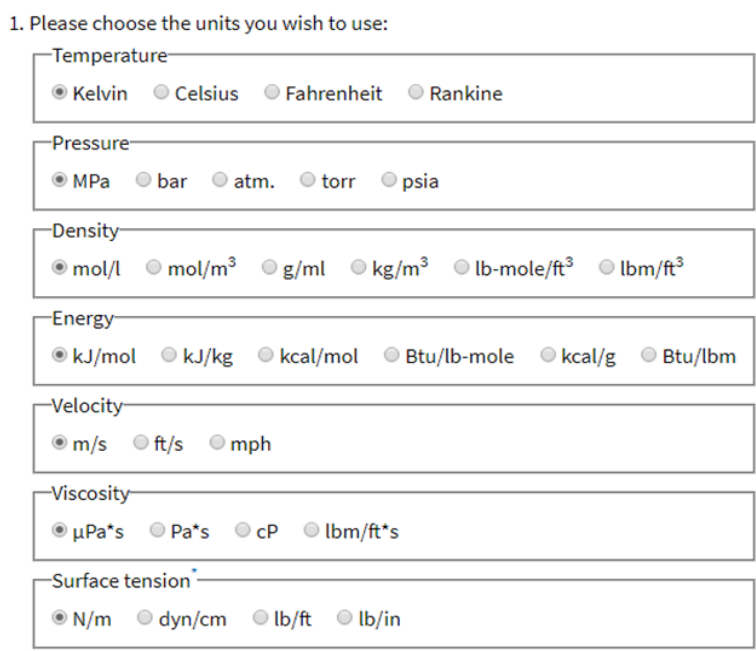

"Surface tension values are only available along the saturation curve.

Figure $4 \mathrm{~A}$ snapshot of the online database (NIST Chemistry Web Book) when attempting to display the Fluid Properties of water.

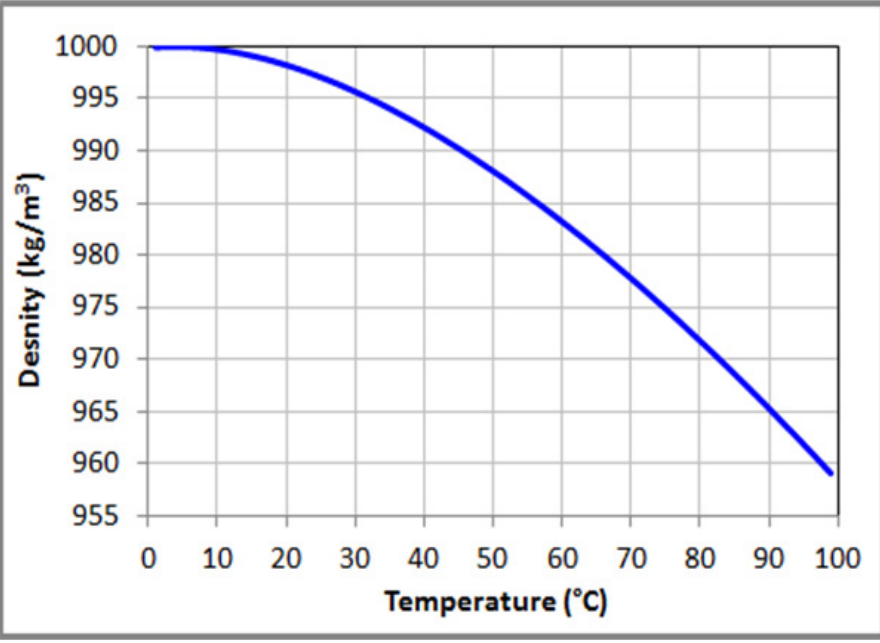

Figure $\mathbf{5}$ Variation of the density with temperature for liquid water at Ibar based on the data obtained from NIST Chemistry Web Book.

The following formulas provide conversions factors from other units used for the above properties to the ones used here: ${ }^{7-9}$

$$
\begin{aligned}
& \frac{\mathrm{lb}_{m}}{\mathrm{in}^{3}}=2.768 \times 10^{4} \frac{\mathrm{kg}}{\mathrm{m}^{3}} \\
& \frac{\mathrm{lb}_{m}}{\mathrm{ft}^{3}}=16.02 \frac{\mathrm{kg}}{\mathrm{m}^{3}} \\
& \frac{\mathrm{slug}}{\mathrm{ft}^{3}}=515.4 \frac{\mathrm{kg}}{\mathrm{m}^{3}} \\
& \frac{\mathrm{g}}{\mathrm{cm}^{3}}=10^{3} \frac{\mathrm{kg}}{\mathrm{m}^{3}}
\end{aligned}
$$

Citation: Marzouk OA. Thermo physical chemical properties of fluids using the free NIST chemistry web book database. Fluid Mech Res Int . 20I7; (I):I4-I8. DOI: 10.15406/fmrij.2017.01.00003 
$\frac{\mathrm{m}^{3}}{\mathrm{~kg}}=10^{3} \frac{\mathrm{cm}^{3}}{\mathrm{~g}}$

Pa.s $=10^{3} \mathrm{cP}$

poise $\left(\frac{\text { dyn.s }}{\mathrm{cm}^{2}}\right)=100 \mathrm{cP}$

reyns $\left(\frac{\mathrm{lb}_{f} \mathrm{~s}}{\mathrm{in}^{2}}\right)=6.895 \mathrm{cP}$

$\frac{\mathrm{mm}^{2}}{\mathrm{~s}}=\mathrm{cSt}$

stokes $\left(\frac{\mathrm{cm}^{2}}{\mathrm{~s}}\right)=100 \mathrm{cSt}$

$\frac{\mathrm{m}^{2}}{\mathrm{~s}}=10^{6} \mathrm{cSt}$

$\frac{\mathrm{in}^{2}}{\mathrm{~s}}=645.2 \mathrm{cSt}$

$\frac{\mathrm{ft}^{2}}{\mathrm{~s}}=9.290 \times 10^{4} \mathrm{cSt}$

$\frac{\mathrm{J}}{\mathrm{kg} . \mathrm{K}} 10^{3} \frac{\mathrm{J}}{\mathrm{g} .{ }^{\circ} \mathrm{C}}$

$\frac{\mathrm{Btu}}{\mathrm{lb}_{m} \cdot{ }^{\circ} \mathrm{F}}=4.187 \frac{\mathrm{J}}{\mathrm{g} .{ }^{\circ} \mathrm{C}}$

$\frac{\mathrm{Btu}}{\mathrm{hr} . \mathrm{ft} .{ }^{\circ} \mathrm{F}}=1.731 \frac{\mathrm{W}}{\mathrm{m} .{ }^{\circ} \mathrm{C}}$

$\frac{\mathrm{km}}{\mathrm{h}}=\frac{1}{3.6} \frac{\mathrm{m}}{\mathrm{s}}=0.2778 \frac{\mathrm{m}}{\mathrm{s}}$

$\frac{\mathrm{ft}}{\mathrm{s}}=0.3048 \frac{\mathrm{m}}{\mathrm{s}}$

$\frac{\mathrm{mi}}{\mathrm{h}}=0.44704 \frac{\mathrm{m}}{\mathrm{s}}$

Four of the above properties are related as following viscosities are related as:

$$
\begin{gathered}
\text { specific volume }=\frac{1}{\text { density }} \\
\text { kinematic vis } \cos \text { ity }=\frac{\text { dynamic viscos ity }}{\text { density }}
\end{gathered}
$$

\section{Validation}

To judge the accuracy of the values in the NIST Chemistry Web Book, we compare selected values taken for the properties of water as taken from that database with those available in two other sources. The first source is appendix $\mathrm{C}$ in a classic reference in the area of water treatment. ${ }^{10}$ The second source is a software package. ${ }^{11}$ The comparisons are made at one standard atmospheric pressure $(101,325$ $\mathrm{Pa}$ ) for the isobaric (constant-pressure) water data of density in Table 3 and for dynamic viscosity in Table 4 . The fluid is water in both tables. The values taken from the NIST Chemistry Web Book database agree well (and sometimes are identical to) those taken from the other sources. This agreement suggests that the database was prepared carefully and can be used reliably.

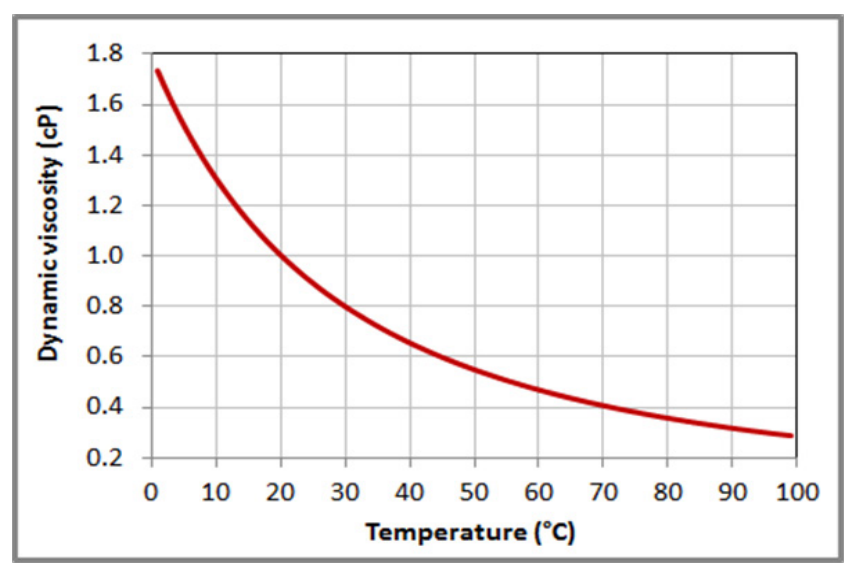

Figure $\mathbf{6}$ Variation of the dynamic viscosity with temperature for liquid water at Ibar based on the data obtained from NIST Chemistry Web Book.

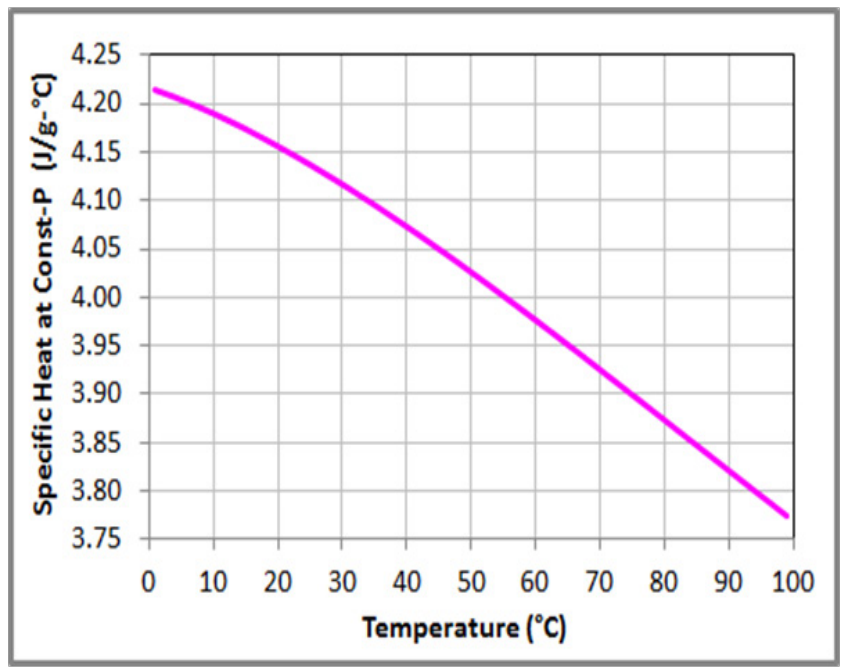

Figure 7 Variation of the specific heat capacity at constant pressure with temperature for liquid water at Ibar based on the data obtained from NIST Chemistry Web Book.

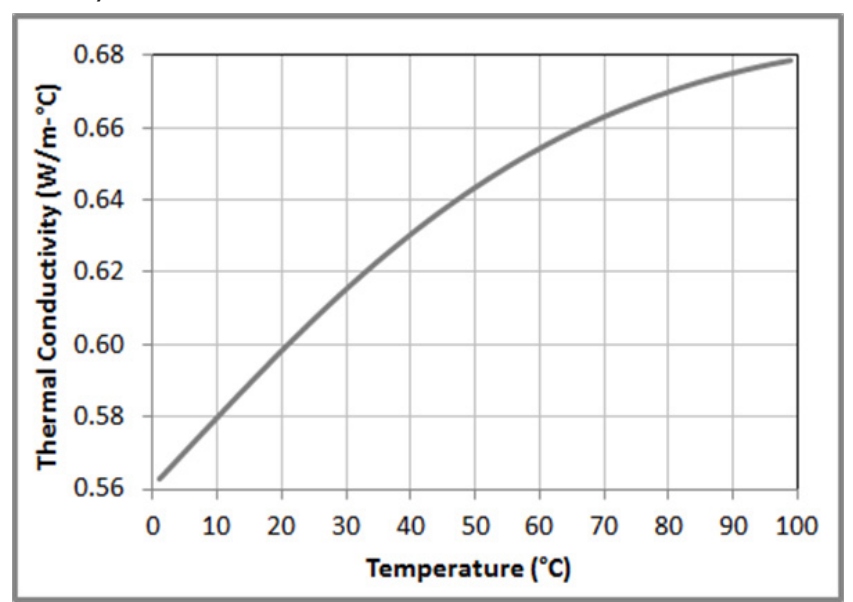

Figure 8 Variation of the thermal conductivity with temperature for liquid water at Ibar based on the data obtained from NIST Chemistry Web Book. 
Table 3 Comparing some values of the density (in $\mathrm{kg} / \mathrm{m}^{3}$ ) at 101,325 $\mathrm{Pa}$ from the NIST Chemistry Web Book and two other sources

\begin{tabular}{llll}
\hline Temperature $\left({ }^{\circ} \mathbf{C}\right)$ & NIST & Reference $^{10}$ & Reference $^{\prime \prime}$ \\
\hline 10 & 999.7 & 999.7 & 999.8 \\
20 & 998.2 & 998.2 & 998.3 \\
30 & 995.6 & 995.7 & 995.7 \\
40 & 992.2 & 992.2 & 992.3 \\
50 & 988 & 988 & 988 \\
60 & 983.2 & 983.2 & 983.1 \\
70 & 977.8 & 977.8 & 977.6 \\
80 & 971.8 & 971.8 & 971.6 \\
90 & 965.3 & 965.3 & 965.1 \\
\hline
\end{tabular}

Table 4 Comparing some values of the dynamic viscosity (in cP) at I0I,325 Pa from the NIST Chemistry Web Book and two other sources

\begin{tabular}{llll}
\hline Temperature $\left({ }^{\circ} \mathbf{C}\right)$ & NIST & Reference $^{10}$ & Reference $^{I I}$ \\
\hline 10 & 1.306 & 1.307 & 1.306 \\
20 & 1.002 & 1.002 & 1.002 \\
30 & 0.797 & 0.798 & 0.797 \\
40 & 0.653 & 0.653 & 0.653 \\
50 & 0.547 & 0.547 & 0.547 \\
60 & 0.466 & 0.466 & 0.466 \\
70 & 0.404 & 0.404 & 0.404 \\
80 & 0.354 & 0.354 & 0.354 \\
90 & 0.314 & 0.315 & 0.314 \\
\hline
\end{tabular}

\section{Conclusion}

This article gave a brief overview of the NIST Chemistry Web Book database, which can be very useful when studying, performing engineering design dealing with, or conducting research on fluids as well as other chemical species. An example was given where the constant-pressure variations of four properties were obtained using that database. A comparison between the values in this online database and other two sources for some properties of water at some conditions showed good agreement. Interested readers are encouraged to explore the capabilities of this free and user-friendly online database.

\section{Acknowledgements}

None.

\section{Conflicts of interest}

The author declares that there is no conflict of interest.

\section{References}

1. US Department of Commerce. Standard Reference Data. National Institute of Standards and Technology (NIST), USA.

2. US Department of Commerce. NIST Chemistry WebBook. The National Institute of Standards and Technology (NIST), USA.

3. US Department of Commerce. Search for Species Data by Chemical Formula. National Institute of Standards and Technology (NIST), USA.

4. US Department of Commerce. Search Results for Chemical Formula $\mathrm{H}_{2} \mathrm{O}$. National Institute of Standards and Technology (NIST), USA.

5. US Department of Commerce. Water. National Institute of Standards and Technology (NIST), USA.

6. US Department of Commerce. Thermophysical Properties of Water. National Institute of Standards and Technology (NIST), USA.

7. MM Khonsari, ER Booser. Applied Tribology: Bearing Design and Lubrication. In: Neale MJ, Priest M, Stachowiak G, editors. 2nd ed. USA: John Wiley \& Sons; 2008. 578 p.

8. KK Kuo, R Acharya. Applications of Turbulent and Multiphase Combustion. USA: John Wiley \& Sons; 2012. 600 p.

9. LR Jenkinson, P Simpkin, D Rhodes. Civil Jet Aircraft Design. 1st ed. UK: Butterworth-Heinemann; 1991. $432 \mathrm{p}$.

10. JC Crittenden, RR Trussell, DW Hand, et al. MWH's Water Treatment: Principles and Design. 3rd ed. USA: John Wiley \& Sons; 2012. 1920 p.

11. VAXA Software. Properties of Water. Chicago. USA; 2017. 